\title{
High Heat Flux Erosion of Carbon Fibre Composite Materials in the TEXTOR Tokamak*
}

\author{
RECENVED \\ A. Hassanein \\ SEP 211999 \\ Q.STI \\ Argonne National Laboratory, Argonne, IL 60439, USA \\ H. Bolt, T. Scholz, K.H. Finken
}

Forschungszentrum Jülich GmbH, D-52425 Jülich, Germany

\begin{abstract}
J. Boedo La Jolla, CA 920-93-0417, USA

January 1998
\end{abstract}

University of California, San Diego, Fusion Energy Program,

Presented at the Eighth International Conference on Fusion Reactor Materials (ICFRM-8)

October 26-31, 1997, Sendai, Japan.

"Work supported by the U.S. Department of Energy, and by the Federal Republic of Germany. 


\section{DISCLAIMER}

This report was prepared as an account of work sponsored by an agency of the United States Government. Neither the United States Government nor any agency thereof, nor any of their employees, make any warranty, express or implied, or assumes any legal liability or responsibility for the accuracy, completeness, or usefulness of any information, apparatus, product, or process disclosed, or represents that its use would not infringe privately owned rights. Reference herein to any specific commercial product, process, or service by trade name, trademark, manufacturer, or otherwise does not necessarily constitute or imply its endorsement, recommendation, or favoring by the United States Government or any agency thereof. The views and opinions of authors expressed herein do not necessarily state or reflect those of the United States Government or any agency thereof. 


\section{DISCLAIMER}

Portions of this document may be illegible in electronic image products. Images are produced from the best available original document. 
High Heat Flux Erosion of Carbon Fibre Composite Materials in the TEXTOR Tokamak

H. Bolt, T. Scholz, J. Boedo*, KH. Finken, A. Hassanein ${ }^{*}$

Forschungszentrum Jülich GmbH, Association EURATOM-KFA, D-52425 Jülich, Germany

*:University of California, Fusion Energy Program, San Diego, CA 92093, USA

**: Argonne National Laboratory, Fusion Power Program, Argonne, IL 60439, USA

During plasma disruptions, ELMs, or vertical displacement events (VDEs) high transient heat loads to the plasma facing materials can cause damage such as thermal erosion, cracking, or melting. Self shielding processes, which take place when a material surface is exposed to a high heat flux from an incident plasma, can lead to a reduction of the deposited energy.

Experiments using the fast pneumatic probe of the TEXTOR tokamak were carried out to investigate these effects. The materials tested were carbon fibre reinforced materials with and without Si-addition. The probe with the material specimens was introduced into the edge plasma up to a depth of $9 \mathrm{~cm}$ in front of the ALT-II main limiter with a residence time of $80 \mathrm{~ms}$.

After the repeated exposure to the TEXTOR-plasma, the material specimens were examined by profilometry and electron microscopy to determine the damage and erosion. It was found that only a very limited zone of the probe tip of about 2.5 $\mathrm{mm}$ extension in radial direction showed erosion. The maximum erosion was observed at the very tip of the probe with approx. $30 \mu \mathrm{m}$ per exposure. The results of the erosion quantification are compared with the results from numerical simulations and from plasma diagnostic measurements during the exposure of the specimens. 


\section{Introduction}

Plasma instabilities in tokamak fusion devices can cause the deposition of high transient heat fluxes to the plasma facing components and result in damage of the plasma facing material like ablation erosion, melting, and crack formation. Instabilities like edge localised modes (ELMs), vertical displacement events (VDEs) and disruptions lead to increased fluxes of plasma particles and energy on local areas, especially on divertor and limiter surfaces. In a next generation tokamak like ITER the theoretical thermal energy deposition in such cases can be of the order $10 . . .100 \mathrm{MJ} / \mathrm{m}^{2}$ on a time scale of $1 . .300 \mathrm{~ms}$, depending on the kind of plasma instability $11 /$. The thermal ablation of the plasma facing material, which is caused by the direct deposition of such thermal loads could reach $100 \mathrm{~s}$ of $\mu \mathrm{m}$ and would lead to very short component life times $/ 2-4 /$. So-called "vapour shielding" processes, which summarize a complex dynamical sequence of interaction processes between incident plasma, ablated vapour and the plasma facing material itself, can lead to a strong reduction of the energy density which is actually deposited in the plasma facing material /5-8/.

Due to these processes the amount of material damage and ablation can be reduced strongly. In experiments with a fast pneumatically driven probe in the TEXTOR tokamak the evolution of a strongly radiating vapour cloud in front of the exposed materials was visualised and it was shown that the boundary plasma is strongly cooled by the influx of the ablated impurity atoms /9-11/.

In the work presented in this paper two composite materials, a pure carbon CFC and a CFC with 10\% Si addition have been exposed to high heat flux pulses in the TEXTOR plasma using a fast reciprocating probe (UCSD-probe). The erosion of the materials during exposure was derived from the variation of the electron density as well as from profilometry measurements of the specimen surfaces after exposure. The results of these measurements were used for a numerical simulation with the aim to approximate the actually deposited heat flux distribution on the specimen surface. In addition, the morphology of the specimens was analysed after exposure and discussed with regard to the plasma-material interaction processes which took place. 


\section{Experimental}

CFC specimens were exposed to high heat fluxes from the TEXTOR plasma by use of a pneumatically driven fast probe of the UCSD-team 19,10/. The specimens were mounted to a probe shaft which allowed fast strokes into the plasma and thus the exposure of the specimens to transient heat fluxes. The typical duration of the in and out movement was about $20 \mathrm{~ms}$ each. At the end position with the material specimen being introduced into the TEXTOR tokamak plasma up to 9 $\mathrm{cm}$ deep in front of the main limiter radius the dwell time was $80 \mathrm{~ms}$. The specimens had a quadratic cross section of $16 \mathrm{~mm} \times 16 \mathrm{~mm}$ with a length of $120 \mathrm{~mm}$. With regard to the plasma the probe tip was at floating potential and electrically isolated against other components.

Three different materials were used in the experiments. A 2-d woven CFC (Schunk CF 260) with very low thermal conductivity, was used for first pre-tests with the aim to maximise the carbon erosion during plasma exposure. Results of these first experiments are described in /9/. For further experiments with extensive local diagnostic measurements fusion relevant materials were used, SEPCARB N11, a pure carbon 2- $d$ felt CFC with needling reinforcement and high thermal conductivity and SEPCARB NS11, a similar CFC with $10 \%$ Si added during the impregnation process, material data s. table 1.

The $\mathrm{N} 11$ specimen was inserted $9 \mathrm{~cm}$ into the boundary plasma in front of the main limiter. This was repeated for ten discharges without causing disruptions. The NS11 specimen containing $10 \%$ Si could only be inserted $6 \mathrm{~cm}$ into the boundary plasma without causing disruptions. This specimen was exposed to 30 discharges at $6 \mathrm{~cm}$ insertion depth.

The plasma parameters as they were measured in the undisturbed plasma at the max. insertion depth ( $9 \mathrm{~cm}$ for $\mathrm{N} 11$ and $6 \mathrm{~cm}$ for NS11) are listed in table 1. The incident heat flux from the undisturbed plasma onto a surface was calculated from $n_{e}$ and $T_{e}$ assuming an energy transmission factor through the plasma sheath of 8 $111,12 /$. The resulting values of the initial incident heat flux to the probe tip are $Q$ $(N 11)=23 \mathrm{~kW} / \mathrm{cm}^{2}$ and $Q(N S 11)=8.2 \mathrm{~kW} / \mathrm{cm}^{2}$.

The effects of the probe insertion on the evolution of the plasma parameters and the emitted radiation in the plasma were investigated by $\mathrm{HCN}$-interferometry for electron density and temperature measurements, He-beam diagnostics, optical emission spectroscopy (OES) and bolometry. For the fast imaging of the radiating 
cloud which forms in front of the specimen surface during plasma exposure a CCD camera was used $/ 111$.

The erosion and damage of the specimens was determined by measuring surface profiles by mechanical and laser profilometry before and after exposure to the plasma and also by SEM observation as well as EDX-analyses.

\section{Results}

\subsection{Erosion estimate derived from increase of plasma density}

The tests of the N11-material and the Si-containing NS-11 material were carried out in ohmic plasma discharges of similar characteristics, i.e. plasma density and temperature profiles before probe insertion. The N11-specimen was introduced to a depth of $9 \mathrm{~cm}$ in front of the main limiters without causing plasma disruptions (10 exposures). With the Si-containing NS11 disruptions occurred at $9 \mathrm{~cm}$ insertion depth. Thus most exposures of this material (30 exposures) were performed at an insertion depth of $6 \mathrm{~cm}$. The corresponding plasma parameters $T_{e}, n_{e}$ and heat fluxes $Q$ of the undisturbed plasma in the tip region of the probe for the two materials are given in tab. 1.

The evolution of the electron number in a typical discharge with exposure of $\mathrm{N} 11$ to an insertion depth of $9 \mathrm{~cm}$ is shown in figure 1. The erosion of atoms from the probe tip and the subsequent ionization of the eroded atoms in the plasma causes the increase of the total number of electrons present in the plasma. From the increase of the electron number and the decay after probe retraction the influx of impurity atoms from the probe tip can be estimated $19 /$. The average confinement time of the impurity induced electrons was derived from the decay of the electron number after retraction of the probe from the hot plasma. For N11 this gave an approximate confinement time $\tau_{p}=60 \mathrm{~ms}$ and for the Si-containing material NS11 $\tau_{p}$ $=100 \mathrm{~ms}$. Figure 1 shows the numerical approximation of the electron generation from the ionization of the inflowing impurity atoms and the subsequent loss of these electrons from the discharge. For the estimate of the inflow of impurity atoms which was derived from the variation of the electron number in the plasma it was assumed that in the case of the N11 material, where only C-atoms were eroded, these Catoms $(Z=6)$ were fully ionised within the plasma which leads to the liberation of six electrons per C-atom. In the case of NS11 it was assumed that preferentially Si entered the plasma due to the significantly higher vapour pressure compared to $C$ 
113/. For the eroded Si $(Z=14)$ atoms ionization up to SiXII was assumed, since the innermost electrons require rather high energy for ionization. The resulting evaporation of material for one exposure was for N11: 1.2.1019 atoms C, NS11: 1.7. $10^{18}$ atoms $\mathrm{Si}$. The erosion value for the $\mathrm{N} 11$ material is similar to the previously published erosion value for the CFC with low thermal conductivity, CF260, of 1.6. $10^{19}$ atoms C. However, the erosion value of the NS11 material was much lower, which can be attributed to the lower incident heat flux $\left(Q=8.2 \mathrm{~kW} / \mathrm{cm}^{2}\right)$ and also to the better vapour shielding efficiency of $\mathrm{Si}$ atoms in the plasma due to the stronger emission of radiation per impurity atom. Even though the amount of eroded $\mathrm{Si}$ atoms was much smaller in the experiments with NS11 than the amount of eroded C-atoms for $N 11$, the bolometrically measured total energy emitted by radiation was not very different, $Q_{\mathrm{rad}}=10 \mathrm{~kJ}$ for $\mathrm{NS} 11, \mathrm{Q}_{\mathrm{rad}}=15 \mathrm{~kJ}$ for $\mathrm{N} 11$. Thus the radiation emitted per impurity atoms can be estimated to $Q_{r a d}^{\prime}=3.5 \cdot 10^{4} \mathrm{eV}$ per Si atom and $Q_{\text {rad }}^{\prime}=8.3 \cdot 10^{3}$ eV per C-atom.

\subsection{Erosion estimate from profilometry of specimens}

After the experiments the surface profile of the N11 probe tip was measured by laser and stylus profilometry. The side surfaces which were positioned perpendicular to the magnetic field showed erosion, see the representative measurement in figure 2. At the edge the erosion depth reached $300 \mu \mathrm{m}$. In length $(y-)$ direction away from the edge the erosion strongly decreased until a radial distance from the edge of $y \approx 2.5 \mathrm{~mm}$. This indicates that the high heat flux only hit at the very edge of the probe and that the heat flux decay length in radial direction was very small. No significant erosion was measured on the end face of the tip and on the side surfaces which were oriented parallel to the magnetic field. The summation of the erosion volume measured on the surfaces perpendicular to the magnetic field gave a volume of $6.8 \mathrm{~mm}^{3}$, corresponding to a weight loss of $1.2 \mathrm{mg}$ per plasma exposure which gives an ablation of $6 \cdot 10^{19}$ atoms $C$ per plasma exposure for the $\mathrm{N} 11$ material. This is a factor of 5 higher than the estimate of ablated C-atoms from the increase of the electron number in the plasma, cf. 3.1. This difference may have the following reasons:

- The assumption that all ablated $\mathrm{C}$ atoms are ionised to $\mathrm{CVI}$ is incorrect. because a large part of the ablated C-atoms does not reach total ionization, but is 
redeposited with lower charge state already. Thus a larger number of C-atoms would have been eroded. Also it implies that the strong radiation which was measured by bolometry in the boundary was emitted from a plasma of fairly low electron temperature which leads to low charge states of the eroded C-atoms. This would be consistent with the He-beam measurement of very low electron temperatures in the shadow of the inserted probe $111 \%$.

- The erosion value derived from the profilometer measurements should be accurate only within a factor of two.

- The total electron number is derived from a diagnostic at one toroidal location and extrapolated to the whole plasma volume, which may be an uncertain procedure in the case of a strong local impurity source.

A quantitative measurement of the erosion on the NS11 specimen could not be performed, because the erosion pattern at the probe tip was too irregular and the total amount of erosion comparatively small, see cf. 3.4 .

\subsection{Calculation of the energy deposition from the erosion profile}

Calculations were carried out using a 2-d computer code with direction dependent material data for the N11 material. The simulation included thermal conduction, evaporation and radiation from the specimen surface. A starting temperature of $2000 \mathrm{~K}$ was assumed to include the temperature rise of the probe during the inward stroke phase of the probe. The heat flux was assumed as constant over a period of $80 \mathrm{~ms}$. It was found that the erosion profile of fig. 2 could be simulated with an exponentially decaying profile of the deposited heat flux of the shape $Q(y)=Q_{0}{ }^{*} \exp \left(-y / y_{0}\right)$. Values of $Q_{0}$ and $y_{0}$ were systematically varied until satisfying accord was found between the measured and the calculated erosion profile. Figure $3 a, b$ shows the profile of the deposited heat flux with $Q_{0}=12.5$ $\mathrm{kW} / \mathrm{cm}^{2}$ for $80 \mathrm{~ms}, y_{0}=2.7 \mathrm{~mm}$ and the resulting erosion profile per exposure which matches well with the erosion profile accumulated over ten exposures of fig. 2 .

The result shows that the power scrape-off length $\left(y_{0}\right)$ at the probe tip with $2.5 . .3 \mathrm{~mm}$ is very short compared to usual values at TEXTOR limiters of $7 \ldots 10 \mathrm{~mm}$. In addition the average deposited heat flux at the very probe tip is a factor of two lower than the estimated heat flux in the undisturbed plasma, see cf. 2. 


\subsection{Morphology of exposed materials}

N11 (pure carbon), figure 4: The overview image of the probe tip, fig. $4 a$, reveals that the zone of strong erosion is very narrow, similar to the surface profile plot of fig.2. Traces of redeposited carbon are already found at a distance of $>400$ $\mu \mathrm{m}$ from the probe tip. Since these redeposition traces are in a zone where the surface profile still shows gross erosion, fig. 2 , it is assumed that some redeposition occurred during the outward stroke phase of the probe.

The very sharp transition from erosion to redeposition is also shown on a higher magnification image, fig. $4 \mathrm{~b}$, with traces of erosion on the upper part and redeposited carbon in the lower part. The end face of the specimen as well as the other surfaces of the specimen which were not exposed to high heat fluxes are largely covered with redeposited material.

A cross sectional TEM image taken with energy filter reveals a columnar/fibrous growth structure of the redeposited material with the columnar orientation being perpendicular to the specimen surface, fig. 5. Within the amorphous matrix of the redeposited material small graphitized crystallites of approx. $20 \mathrm{~nm}$ diameter were found (dark dots in the within the redeposited material).

NS11 (90\%C, 10\%Si): During production this CFC had been impregnated with approx. $10 \% \mathrm{Si}$. The Si partially reacted to $\mathrm{SiC}$, but also largely remained unreacted and filled the volumes in between C-fibre bundles. The SEM image of the probe tip surface which was oriented perpendicular to the magnetic field is shown in fig. 6. At the upper part of the image and esp. close to the edge of the specimen the Si evaporated and left voids in the carbon base material (EDX-analyses). The preferential evaporation of Si which was observed at the highly loaded specimen tip is due to the higher Si-vapour pressure compared to $\mathrm{C}$. This justifies the assumption that the main species ablated during the exposure of this material was $\mathrm{Si}$, cf. 3.1.

\section{Summary}

Specimens of a pure carbon CFC and of a CFC containing $10 \%$ Si were exposed to high transient heat fluxes from the plasma of the TEXTOR tokamak. The duration of the exposure pulses was $80 \mathrm{~ms}$ and the incident heat fluxes were 23 $\mathrm{kW} / \mathrm{cm}^{2}$ and $8.2 \mathrm{~kW} / \mathrm{cm}^{2}$ resp. Due to the cooling of the boundary plasma upon insertion of the specimens and due to additional local vapour shielding the actually 
deposited heat fluxes were strongly reduced. Erosion estimates of the pure carbon CFC were $1.2 \cdot 10^{19}$ atoms $C$ per exposure as derived from plasma diagnostic measurements or $6.10^{19}$ atoms $C$ per exposure as derived from post-experimental profilometer measurements. Considerable erosion of up to $30 \mu \mathrm{m}$ per exposure occurred only at the very tip of the specimen which was exposed to a heat flux deposition of approx. $12.5 \mathrm{~kW} / \mathrm{cm}^{2}$. The decay length of the power deposition was very short with $2.5 . .3 . \mathrm{mm}$ along the probe. The surface areas which were not exposed to high heat flux were covered with redeposited material. The Si-containing CFC preferentially lost the Si at the highly loaded tip of the specimen. Even though relatively less Si was ablated (estimate $1.7 \cdot 10^{18}$ at per exposure) compared to the experiments on pure carbon, the amount of impurity radiation was of similar order (10 kJ for the Si-containing material, $15 \mathrm{~kJ}$ for the pure carbon $\mathrm{CFC}$ ). 


\section{References}

1. R.R. Parker, W.B. Gauster, Fusion Eng. Des. 30 (1995) 119

2. J. Linke, M. Akiba, H. Bolt, G. Breitbach, R. Duwe, A. Makhankov, I. Ovchinnikov, M. Rödig, E. Wallura, J. Nucl. Mater. 241-243 (1997) 1210

3. J. Linke, M. Akiba, M. Araki, A. Benz, H. Bolt, H. Hoven, K. Koizlik, H. Nickel, M. Seki, E. Wallura in: Proc. 16th Symp. on Fusion Technology (Elsevier, Amsterdam, 1991) pp. 428

4. J.G. v.d. Laan, H.Th. Klippel, G.J. Kraaj, R.C.L. v.d. Stad, J. Linke, M. Akiba, J. Nucl. Mater. 196-198 (1992) 612

5. A. Hassanein, I. Konkashbaev in: Atomic and Plasma-Material Interaction Data for Fusion, Vol. 5 (IAEA, Vienna, 1994) pp.1935.

6. J. Gilligan, D. Hahn, R. Mohanti, J. Nucl. Mater. 162-164 (1989) 957-963

7. H. Bolt, H. Harano, H. Madarame, K. Okamoto, H. Takabe, J. Nucl. Mater. 196198 (1992) 948-952

8. H. Würz, N.I. Arkhipov, V.P. Bakhin et al., J. Nucl. Mater. 212-215 (1994) 13491352

9. T. Scholz, J. Boedo, H. Bolt, R. Duwe, K.H. Finken, D. Gray, A. Hassanein, J. Nucl. Mater. 241-243 (1997) 848-852

10.T. Scholz, J. Boedo, H. Bolt, K.H. Finken, H. Nickel, Report Forschungszentrum Jülich Jüł-3314, 1996

11.H. Bolt, T. Scholz, J. Boedo, K.H. Finken, A. Hassanein, J. Linke, Fusion Engineering and Design, to be published 
12.P.C.Stangeby in: Physics of Plasma Wall Interaction in Controlled Fusion (Plenum Press, New York, 1984) pp.41

13. Y.S. Touloukian, Ed., Thermophysical Properties of High Temperature Solid Materials (Macmillan, New York) 1970 


\section{Table caption}

Table 1: Material data and TEXTOR plasma exposure parameters

\section{Figure captions}

Figure 1: Increase of the electron number in the TEXTOR plasma during the plasma exposure of $\mathrm{N} 11,9 \mathrm{~cm}$ probe insertion into plasma, discharge no. 64246

Figure 2: Laser profilometer measurement on $\mathrm{N} 11$ after 10 plasma exposures, surface was oriented perpendicular to the magnetic field of TEXTOR.

Figure 3: Results of 2-d numerical calculations to simulate the erosion profile near the probe tip (see also fig. 2)
a) Profile of the deposited energy density with $Q_{0}=12.5 \mathrm{~kW} / \mathrm{cm}^{2}$, $y_{0}=2.7 \mathrm{~mm}$

b) Erosion profile per exposure resulting from the energy deposition shown in fig. $3 a$

Figure 4: N11 specimen after 10 plasma exposures; surface was oriented perpendicular to the magnetic field of TEXTOR.

a) Specimen edge with strong erosion (upper half of image), traces of redeposition (lower half of image)

b) Magnified view of the transition zone (upper half: erosion; lower half: redeposition)

Figure 5: TEM image of a cross section with redeposited material

Figure 6: NS11 specimen after 30 plasma exposures; surface was oriented perpendicular to the magnetic field of TEXTOR 


\begin{tabular}{|c|c|c|}
\hline material & N11 & NS11 \\
\hline composition & C & $90 \% \mathrm{C}, 10 \% \mathrm{Si}$ \\
\hline density $\left(\mathrm{g} / \mathrm{cm}^{3}\right)$ & 1.76 & 2.20 \\
\hline thermal conductivity (RT) & & 200 \\
$I(\mathrm{~W} / \mathrm{mK})$ & 180 & 180 \\
$\perp(\mathrm{W} / \mathrm{mK})$ & 10 & 30 \\
\hline no. of TEXTOR exposures & 9 & 6 \\
\hline insertion depth ${ }^{\star}(\mathrm{cm})$ & 300 & 150 \\
\hline electron temp. ${ }^{\star \star}(\mathrm{eV})$ & $510^{12}$ & $510^{12}$ \\
\hline electron density ${ }^{\star \star}\left(\mathrm{cm}^{-3}\right)$ & 23 & 8.2 \\
\hline inc. heat flux ${ }^{\star \star \star}\left(\mathrm{kW}^{2} \mathrm{~cm}^{2}\right)$ & & \\
\hline
\end{tabular}

*: radial direction in front of main limiter radius

**: at max. insertion depth, before specimen insertion

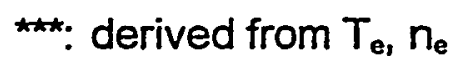

Table 1: Material data and TEXTOR plasma exposure parameters 


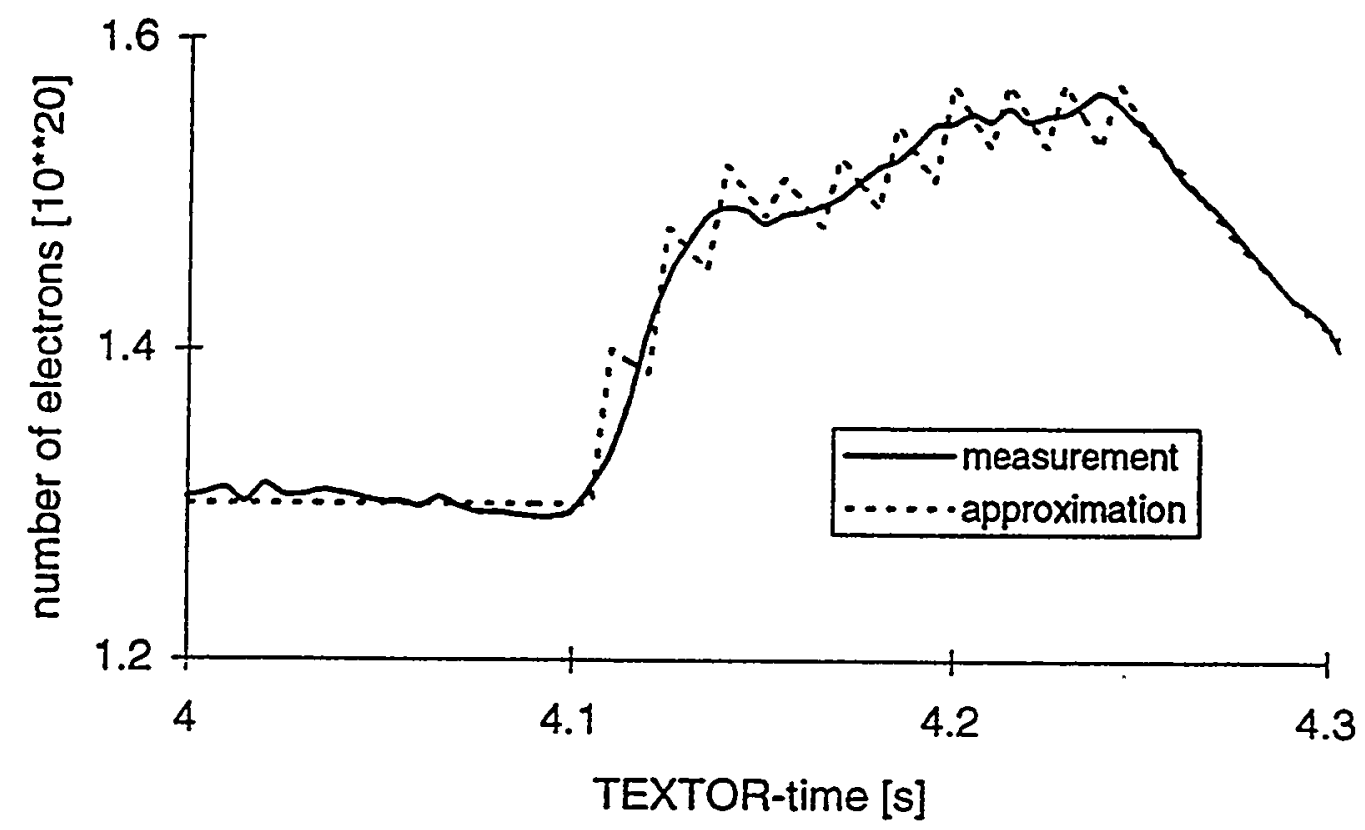

Figure 1 


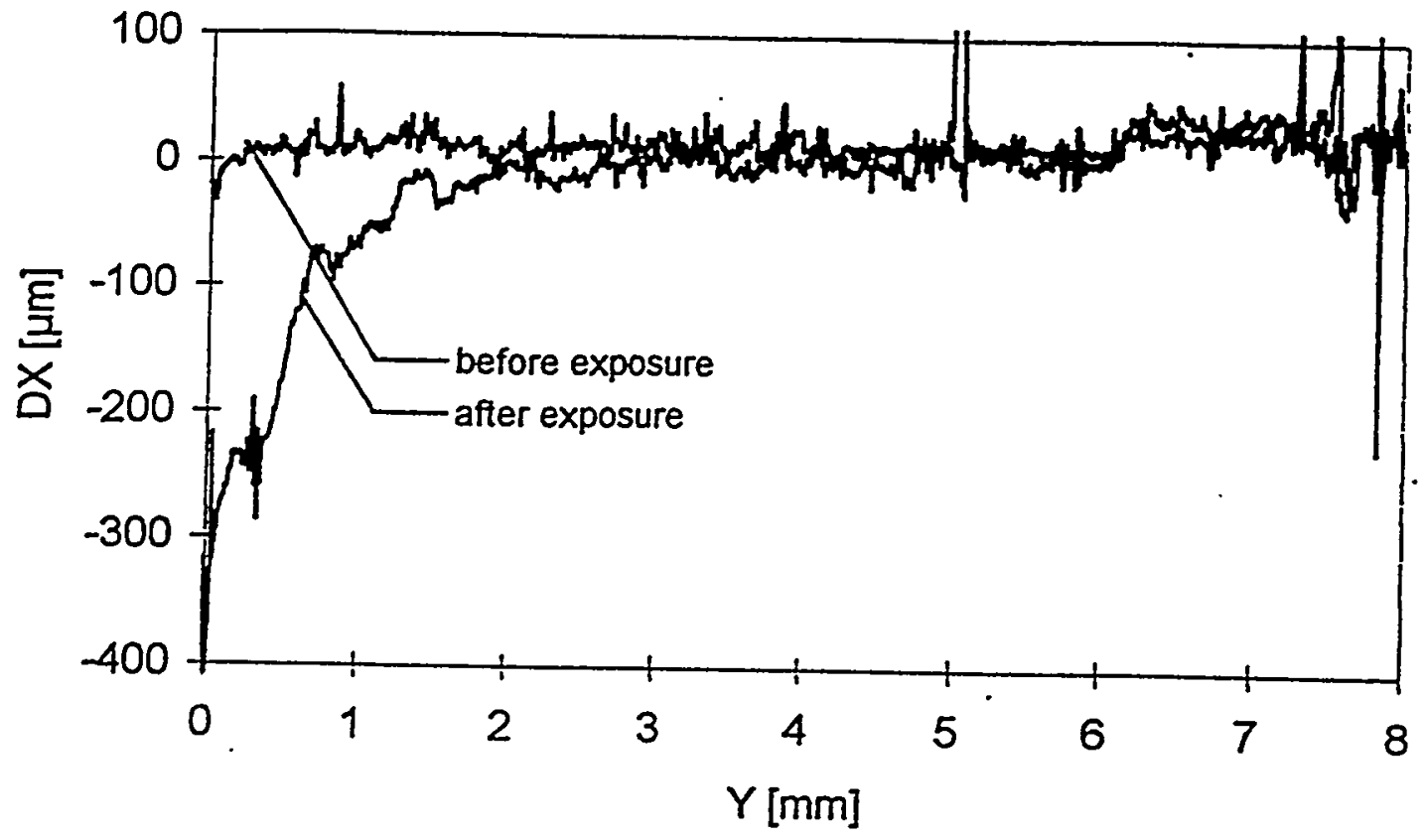

Figure 2 
Figure 3

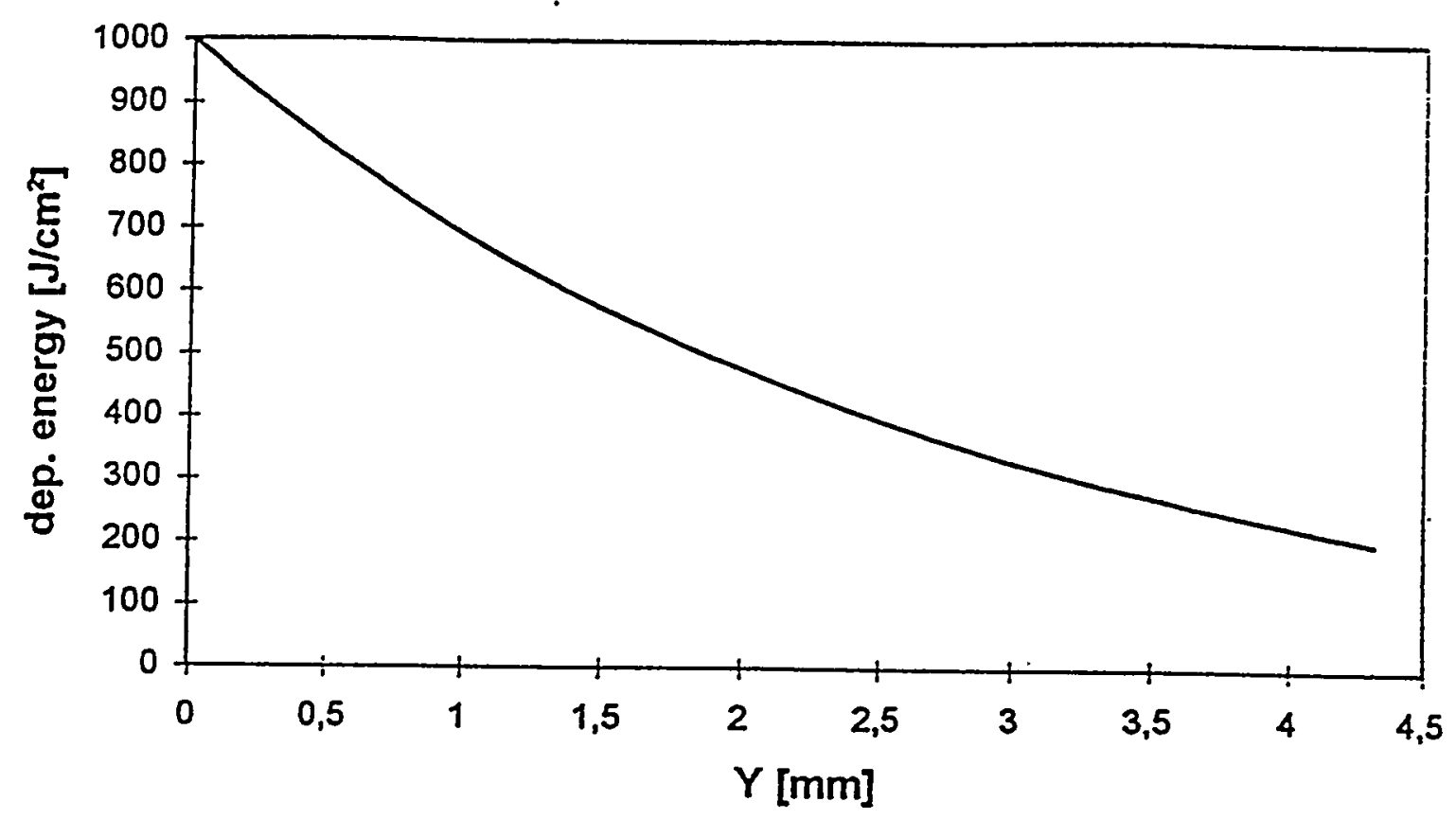

Figure $3 a$

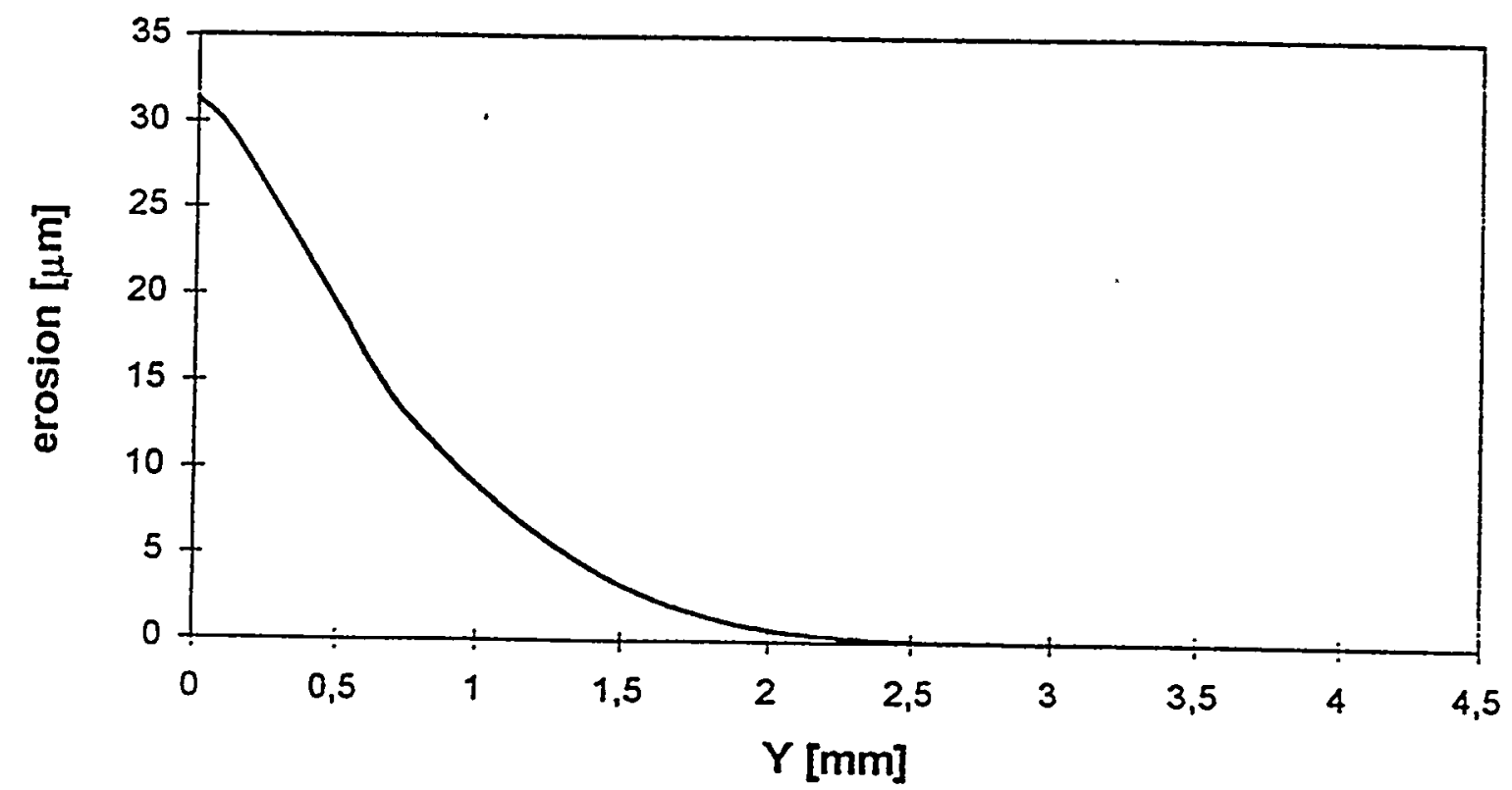

Figure $3 b$ 

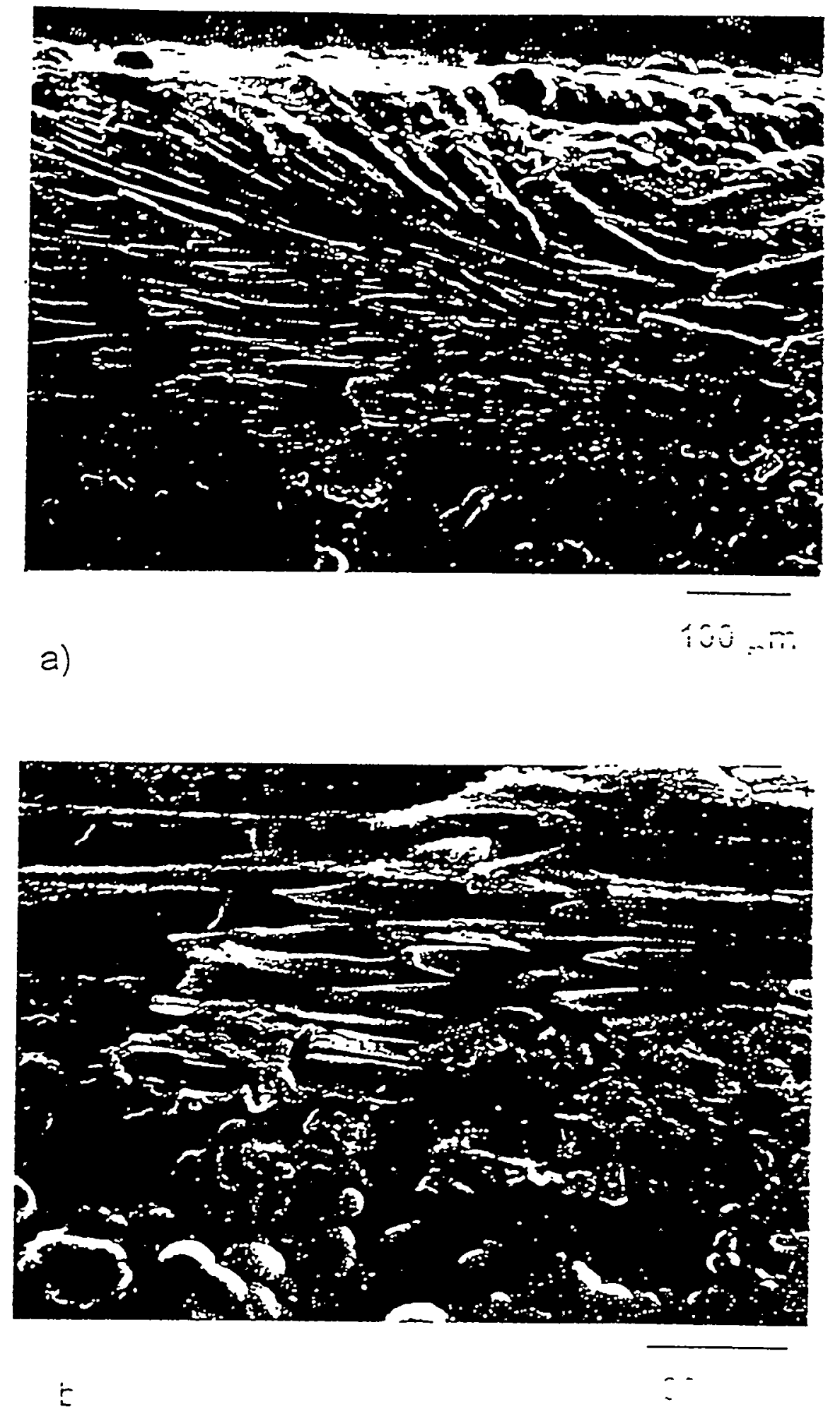

Figu". 


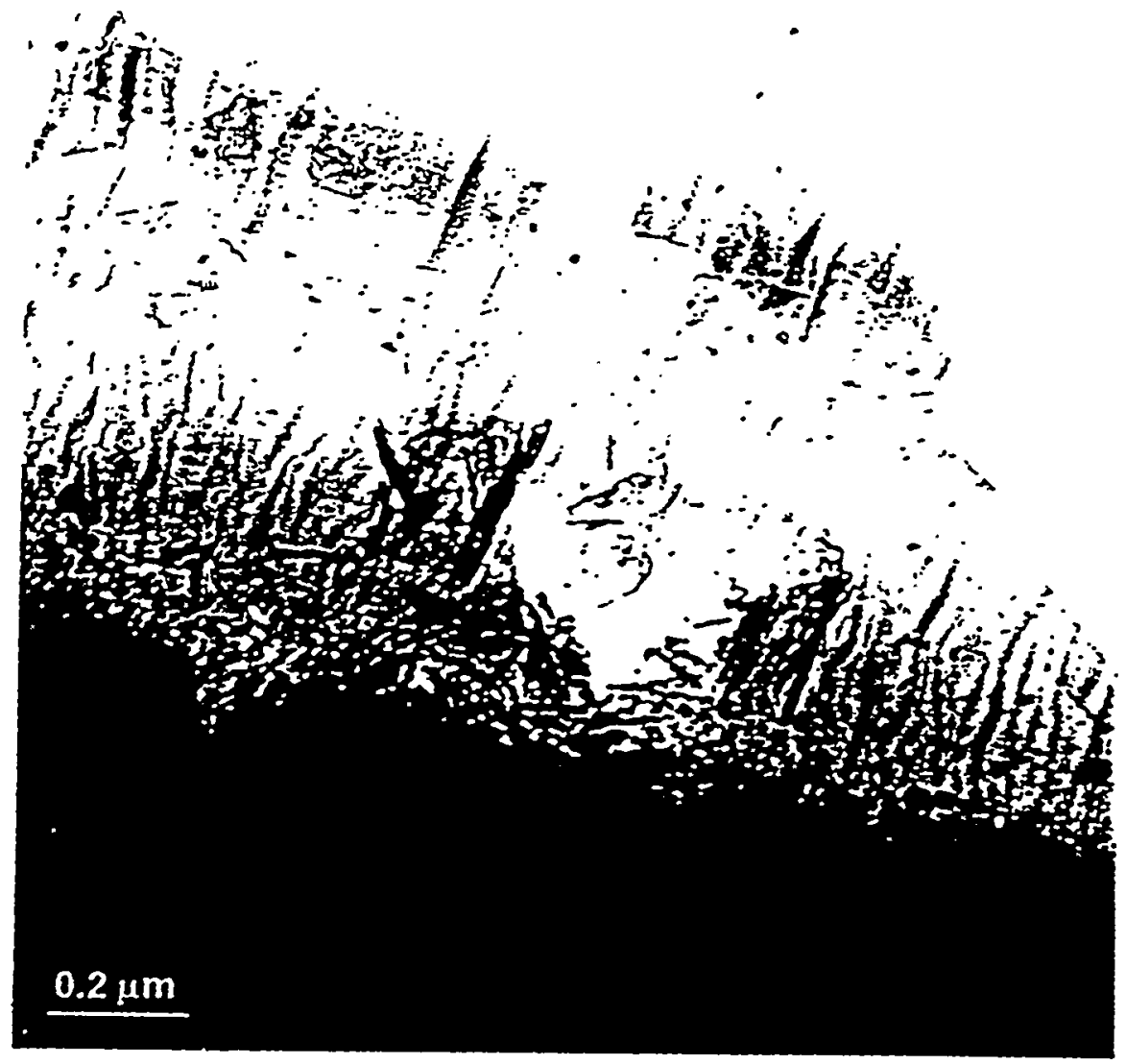

Figure 


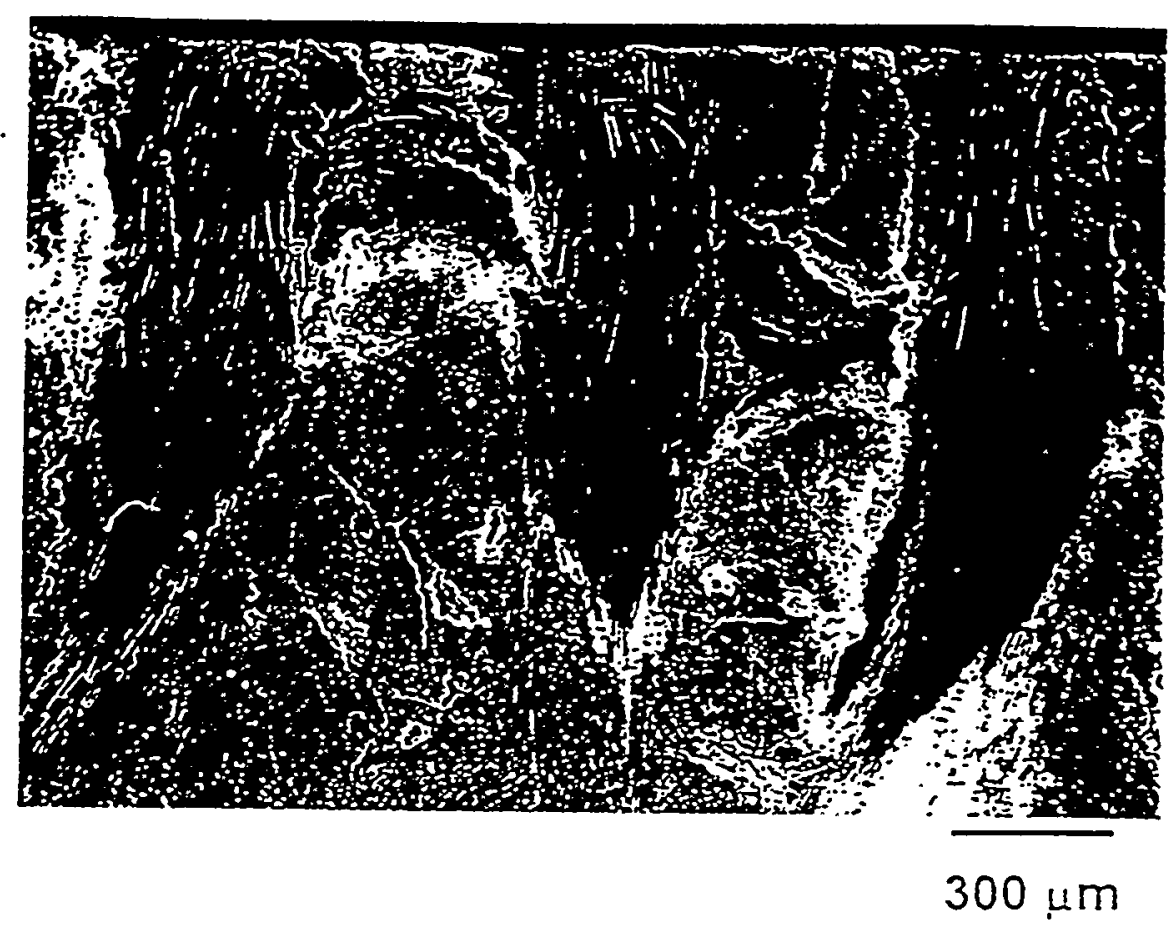

Figure 6 